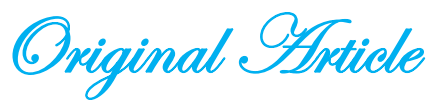

\title{
Psychosocial Impacts of Mentally Retarded Children on Parents in Sudan
}

\author{
Fathia Hussein Shabo ${ }^{1}$, Abdullah A. Rahman Mohamed ${ }^{2}$, \\ Mohamed Omer El Tahir ${ }^{3}$
}

\begin{abstract}
:
This study was conducted on a community sample from Khartoum state, Sudan to explore the psychological and social impacts of the mentally retarded child on his/her parents. The study hypothesized that these effects are directly related to the age, number of handicapped children in the family as well as the degree of mental retardation.

Methods and population: Seven centers for teaching and training of handicapped children were recruited in Khartoum State.

Ninety-one children aged 5-16 years were randomly selected and their intelligence quotient (I.Q) was determined. Interviews for 82 mothers and 64 fathers of these children were held using a standardized anonymous questionnaire including socio-demographic data and information about the psychological and social impacts of the disability of children on their parents. The parents also completed the Hospital Anxiety and Depression Scale (HADS) to assess the presence of anxiety and depression.

Results and discussion: The parents reported different psychological effects when they realized the children's disability. However, they tend to overcome their problem and become adapted to the situation. Sometimes, problems arise in the marital life and in social participation. The research showed that most parents suffered from degrees of anxiety and depression ranging mainly from severe to moderate. The number, age or degree of retardation of the children did not affect the social and psychological impacts on the parents significantly.

The study recommends preventative measures to reduce the factors that lead to mental retardation. It also recommends the provision of rehabilitation services and training of children in schools and special institutes, besides supporting their families psychologically and socially to reduce their burden.
\end{abstract}

Keywords: Anxiety, depression, divorce, marital stability.

$\mathrm{M}$ ental Retardation (MR) affects over 120 million people worldwide. It often gives rise to severe life long standing disability and imposes heavy burden on the families and carers ${ }^{1}$. In Sudan, the population census carried out in 1993, identified many cases of MR and highlighted the negative impact of their disabilities on the parents, families and carers ${ }^{2}$.

Previous studies of the burden of care of mentally retarded children on their families in Sudan showed that many parents suffered with psychological and social effects (unpublished data).

\footnotetext{
1. Assistant Professor of Psychiatry, National Rabat University, Sudan .

2. Consultant Psychiatrist, University of Khartoum Sudan

3. Consultant Psychiatrist, Bro Morgannwg NHS Trust, Wales.
}

However, these studies recruited small number of participants and their results were limited.

Mental Health Services in Sudan focus mainly on provision of Generic adult psychiatric services and no special provision for children and adults with M R. On the other hand many private educational services started to invest in provision of services for people living within the main cities. The reports about the effectiveness of these provisions are yet to come.

This project aims to explore the impacts of care of mentally retarded children on their families within Khartoum State.

\section{Study Objectives:}

To study the distribution of MR in children attending special schools in Khartoum State, Sudan, the psychological impact of care of 
mentally retarded children on their parents, particularly as a factor in causing depression and anxiety, and to identify the impacts of care of mentally retarded children on their parent marital stability and social functioning.

\section{Method:}

This study was designed to obtain information about the psychological and social impacts on the parents resulting from the presence of a mentally retarded child in the family. All children below 16 years of age (personal communication) attending seven centers for mentally retarded children in Khartoum State were approached. Consent for participation in the study was taken from their parents. Seven centres providing education for children with MRwere recruited: Sakina Institute, Fajer Center, Basma Center, Firsan El Erada Center, Child Modern Center, Cenchas Center, Rida School.

Population: A total of 146 parents (64 fathers and 82 mothers) and 91 mentally retarded children were enrolled in the study.

All children had an I.Q. test carried out within the last six months prior to the start of this study. I.Q. test was conducted using the Stanford - Binet test that was adapted to the Sudanese culture by psychologists.

The researcher completed a semi-standardized questionnaire during the interview of the parents. The questionnaire consists of data about the mentally retarded child and his/her parents. The Hospital Anxiety and Depression Scale (HADS) were administered for each parent. The effect on parent's social life was measured using the parent's judgment at interview. Marital stability was assessed and categorized as: strong relationship (S. Relation), another marriage (A. Marriage) and continuous discordance (C. Discord).

Analysis: The data were computerized using the Statistical package SPSS and analyzed using different statistical measures. The level of significance was pre - decided at $\mathrm{p}<0.05$ and confidence intervals at the $95 \%$ level.

\section{Results:}

Demographics: Total number of parents participated in interview were 146 (64 fathers and 82 mothers). These were parents of 91 mentally retarded children, of them 59 were males. Their ages ranged between 5 and 16 years. $73.6 \%$ of children are above 12 years Most children are within the range of mild $(48.4 \%)$ to moderate $(39.5 \%)$ MR while only $7.7 \%$ had severe MR and $4.4 \%$ had profound retardation. $14.6 \%$ of families had more than one mentally retarded child

Divorce rates were low (about 10\% of total marriages. Over $85 \%$ of families reported having stable or even stronger relationship. Nearly $3 \%$ of parents entered a new marriage or had continuous discordance (Fig 1).

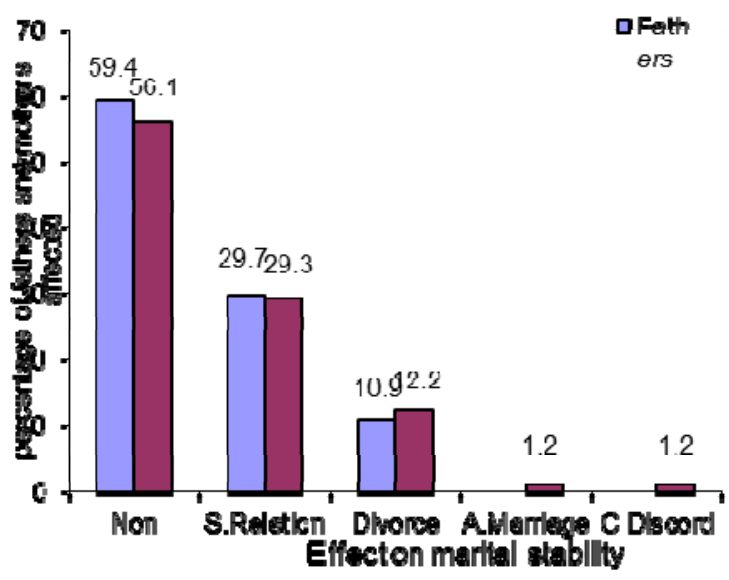

Figure 1: effects on marital stability.

More than $65 \%$ of families reported no effect on their social life from the presence of a mentally retarded child. However, in those $35 \%$ affected families, the mothers were significantly highly affected than the fathers (Fig2).

\section{HADS scores:}

High rates of anxiety were reported by both parents $(70 \%$ of parents reported moderate to severe anxiety scores on the HADS). Only 10 $\%$ of parents did not report anxiety symptoms (Fig3).

Depressive symptoms were also highly reported by parents. $51.2 \%$ of mothers reported moderate depressive symptoms while nearly $30 \%$ reported severe symptoms of depression. Fathers rates were $43.7 \%$ for moderate and also nearly $30 \%$ had sever depressive symptoms. Mild symptoms were also reported in about $18 \%$ of parents (Fig 4). 
Fathia H Shabo et al. Psychosocial Impacts of Mentally Retarded Children on Parents in Sudan

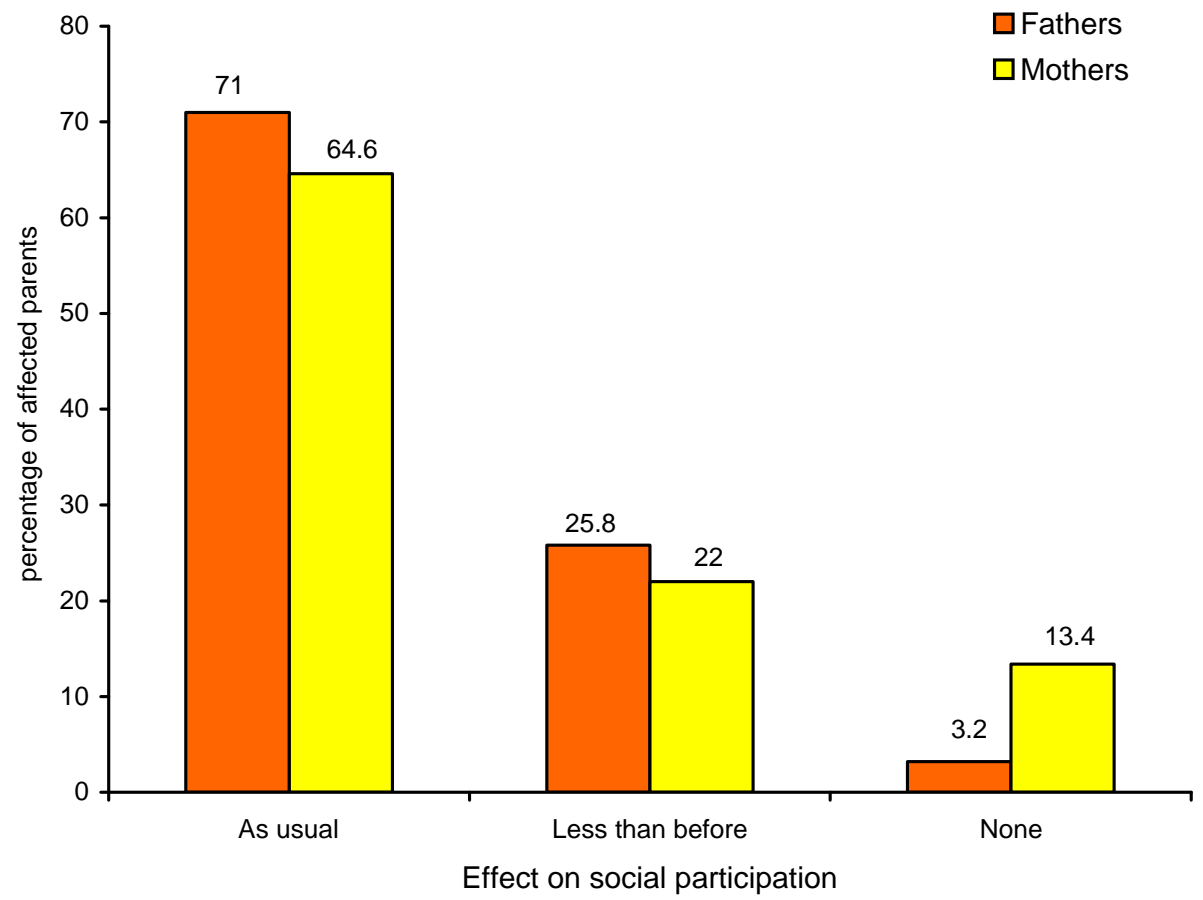

Figure 2: Effects on social participants.

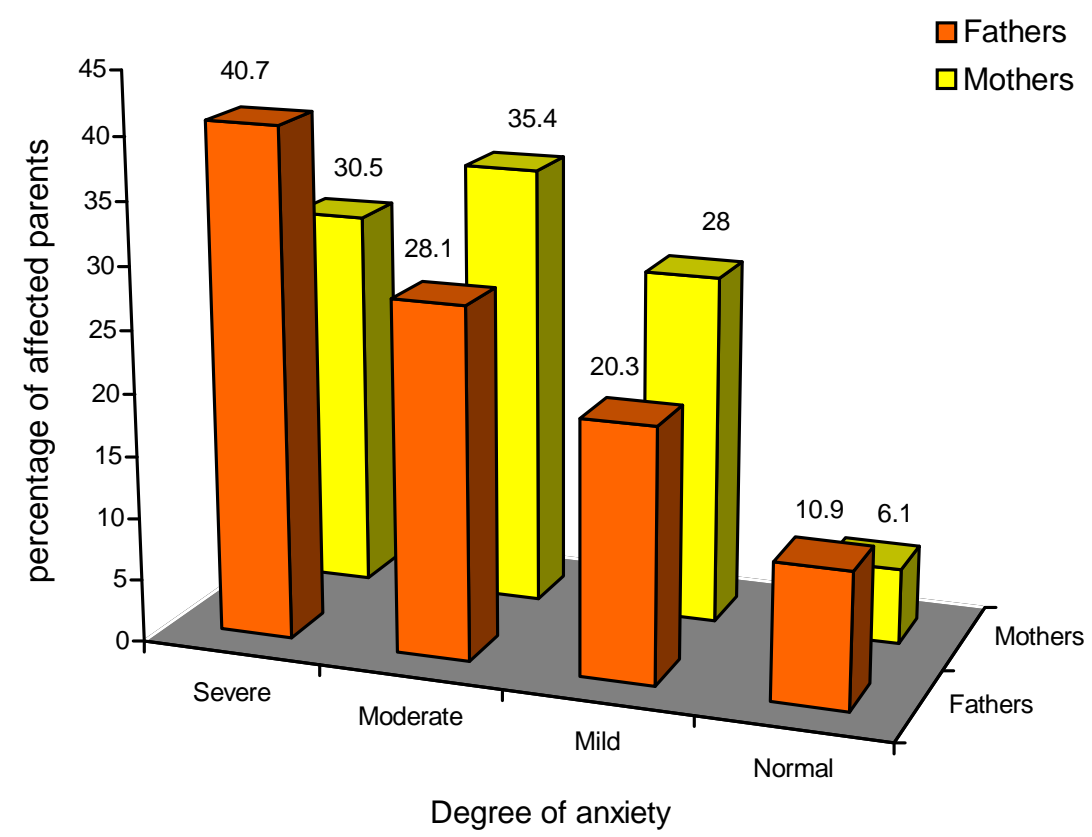

Figure3: Degree of anxiety. 
Fathia H Shabo et al. Psychosocial Impacts of Mentally Retarded Children on Parents in Sudan

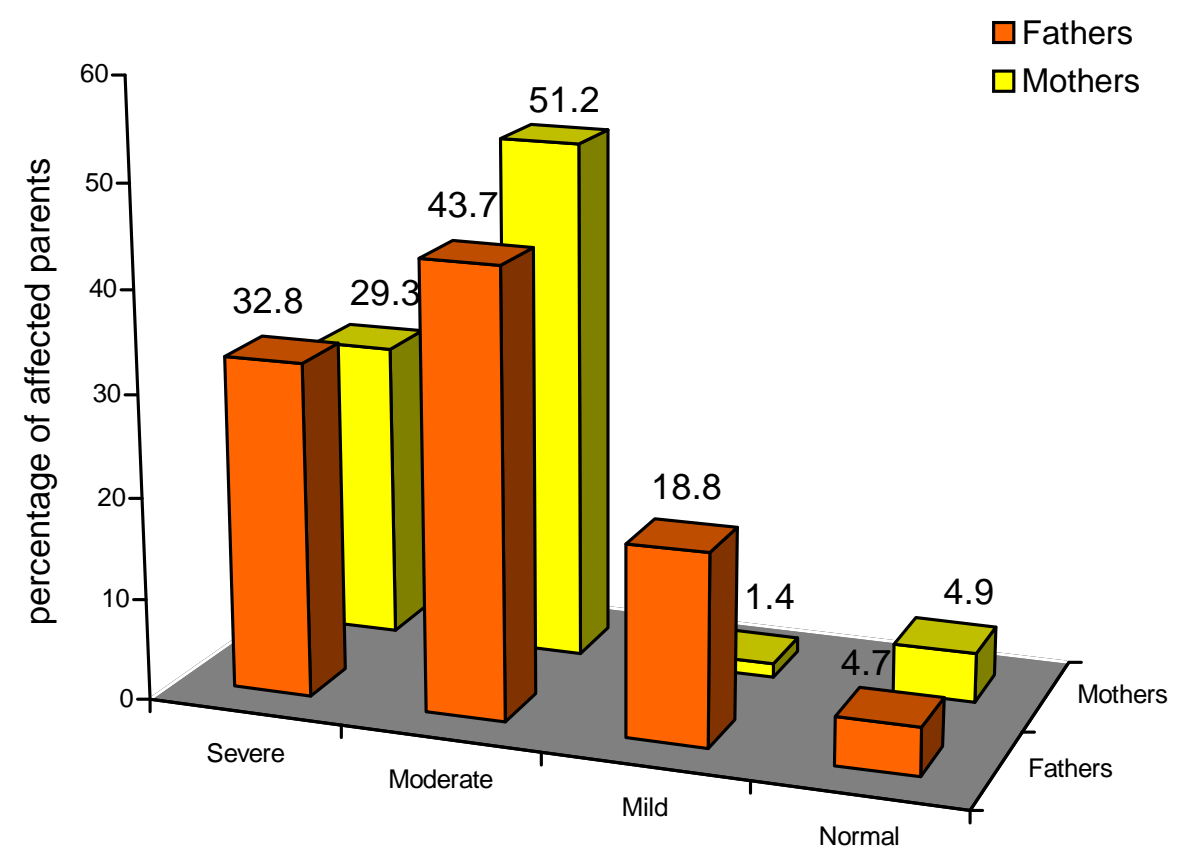

Degree of depression

Figure4: Degree of depression.

Correlation between the age of mentally retarded child and the degree of anxiety and depression was tested and no significant association was found (Table 1).

The severity of anxiety and depressive symptoms were also tested against the presence of more than one child with MR and again showed no significant association between the severity of the symptoms and the number of children with MR (Table 2).

The severity of the anxiety and depressive symptoms in parents and its relation to degree of MR in the child was also studied and showed no significant relationship (Table 3 ). Again no significant association was detected between the marital stability and the age and number of children with MR (Table 4).

Table 1: Degree of depression and anxiety of parents in relation to the age of the mentally retarded child. Number (\%)

\begin{tabular}{|c|c|c|c|c|c|c|c|c|c|}
\hline & \multicolumn{2}{|c|}{ Normal } & \multicolumn{2}{|c|}{ Mild } & \multicolumn{2}{|c|}{ Moderate } & \multicolumn{2}{|c|}{ Severe } & \multirow[t]{2}{*}{$P$ value } \\
\hline & $5-12$ & $>12$ & $5-12$ & $>12$ & $5-12$ & $>12$ & $5-12$ & $>12$ & \\
\hline \multicolumn{10}{|l|}{ Father } \\
\hline $\begin{array}{c}\text { Depress } \\
(\mathrm{n}=4)\end{array}$ & $1(6.3)$ & $2(4.2)$ & $3(18.7)$ & $9(18.8)$ & $5(31.3)$ & $23(47.9)$ & $7(43.7)$ & $14(29.1)$ & $\begin{array}{l}\mathrm{P}=0.64 \\
\mathrm{X}^{2}=1.65\end{array}$ \\
\hline $\begin{array}{l}\text { Anxiety } \\
(\mathrm{n}=64)\end{array}$ & $2(12.5)$ & $5(10.4)$ & $3(18.8)$ & $10(20.8)$ & $2(12.5)$ & $16(33.4)$ & $9(56.2)$ & $17(35.4)$ & $\begin{array}{l}\mathrm{P}=0.36 \\
\mathrm{X}^{2}=3.21\end{array}$ \\
\hline \multicolumn{10}{|l|}{ Mother } \\
\hline $\begin{array}{l}\text { Depress } \\
(\mathrm{n}=82)\end{array}$ & $1(5.0)$ & $3(4.8)$ & $4(20)$ & $8(12.9)$ & $6(30)$ & $36(58.1)$ & $p(45)$ & $15(24.2)$ & $\begin{array}{l}P=0.165 \\
X^{2}=5.08\end{array}$ \\
\hline $\begin{array}{l}\text { Anxiety } \\
(\mathrm{n}=82)\end{array}$ & $0(0)$ & $5(8.1)$ & $6(30)$ & $17(27.4)$ & $5(25)$ & $24(25.8)$ & $9(45)$ & $16(25.8)$ & $\begin{array}{l}\mathrm{P}=0.23 \\
\mathrm{X}^{2}=4.27\end{array}$ \\
\hline
\end{tabular}

Depress $=$ Depression . 
Fathia H Shabo et al. Psychosocial Impacts of Mentally Retarded Children on Parents in Sudan

Table 2: Degree of depression and anxiety of parents in relation to the number of mentally retarded children. Number (\%).

\begin{tabular}{|c|c|c|c|c|c|c|c|c|c|}
\hline & \multicolumn{2}{|c|}{ Normal } & \multicolumn{2}{|c|}{ Mild } & \multicolumn{2}{|c|}{ Moderate } & \multicolumn{2}{|c|}{ Severe } & \multirow[t]{2}{*}{$P$ value } \\
\hline & One & $2+$ & One & $2+$ & One & $2+$ & One & $2+$ & \\
\hline \multicolumn{10}{|l|}{ Father } \\
\hline $\begin{array}{r}\text { Depression } \\
(\mathrm{n}=64)\end{array}$ & $2(3.6)$ & $1(12.5)$ & $10(17.9)$ & $2(25)$ & $25(44.6)$ & $3(37.5)$ & 19(33.9) & $2(25)$ & $\mid \begin{array}{l}\mathrm{P}=0.08 \\
\mathrm{X}^{2}=11.12\end{array}$ \\
\hline $\begin{array}{l}\text { Anxiety } \\
(\mathrm{n}=64)\end{array}$ & $6(10.7)$ & $1(12.5)$ & $11(19.6)$ & $2(25)$ & $17(30.4)$ & $1(12.5)$ & $22(39.3)$ & $4(50)$ & $\begin{array}{l}\mathrm{P}=0.48 \\
\mathrm{X}^{2}=5.50\end{array}$ \\
\hline \multicolumn{10}{|l|}{ Mother } \\
\hline $\begin{array}{r}\text { Depression } \\
\quad(\mathrm{n}=82)\end{array}$ & $4(5.7)$ & $0(0)$ & $10(14.3)$ & $2(16.7)$ & $38(25.7)$ & $6(50)$ & $18(25.7)$ & $6(50)$ & $\mid \begin{array}{l}P=0.26 \\
X^{2}=7.67\end{array}$ \\
\hline $\begin{array}{l}\text { Anxiety } \\
(\mathrm{n}=82)\end{array}$ & $4(5.7)$ & $1(8.3)$ & $22(31.4)$ & $1(8.3)$ & $22(31.4)$ & $7(58.3)$ & $22(31.4)$ & $3(25)$ & $\begin{array}{l}\mathrm{P}=0.36 \\
\mathrm{X}^{2}=6.59\end{array}$ \\
\hline
\end{tabular}

Table 4: The effect on the marital stability of the parents in relation to the number and age of the mentally retarded children in the family. Number $(\%)$

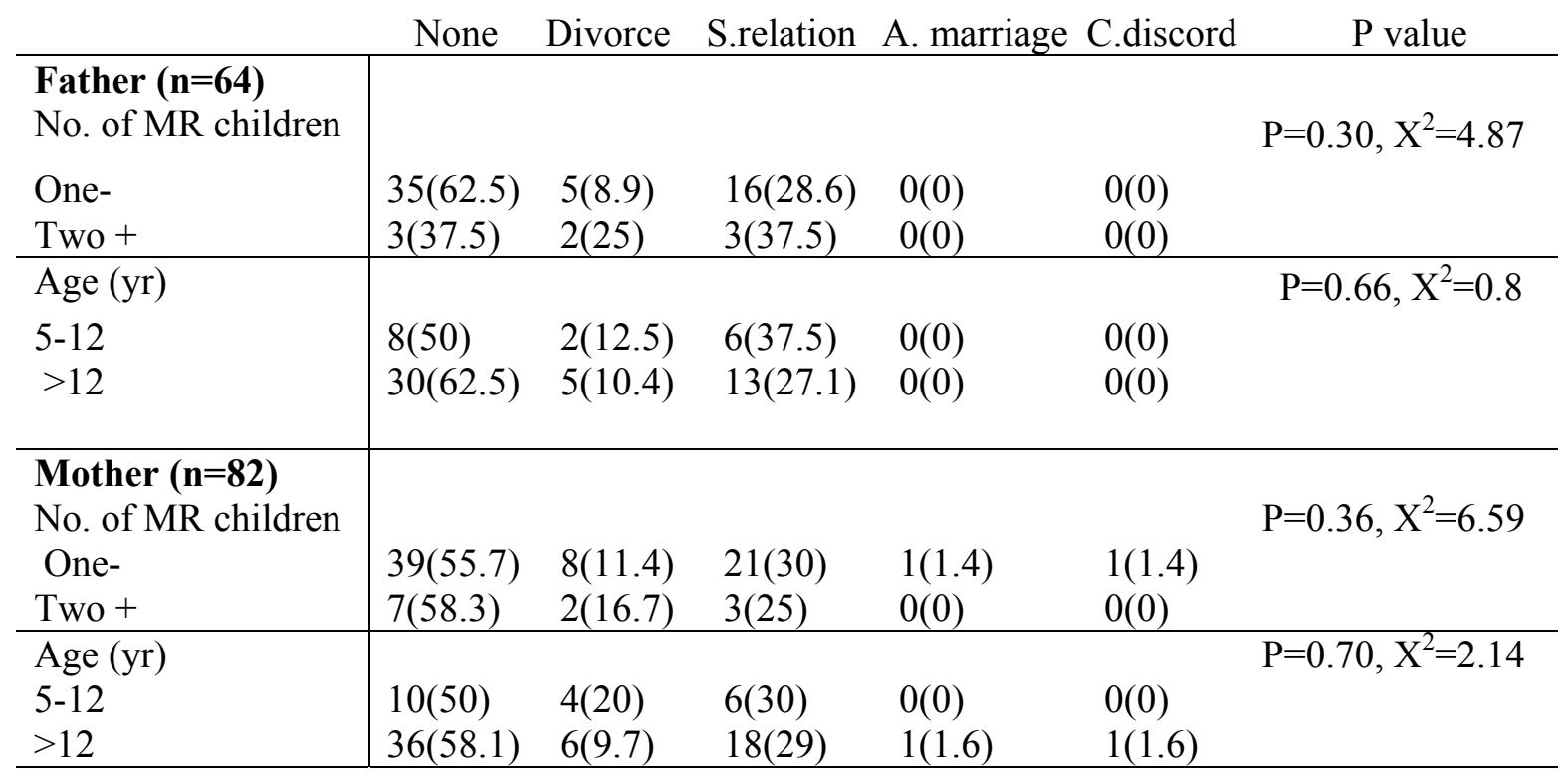


Fathia H Shabo et al. Psychosocial Impacts of Mentally Retarded Children on Parents in Sudan

Table 3: Degree of depression and anxiety of parents in relation to the degree of severity of MRof the child. Number (\%)

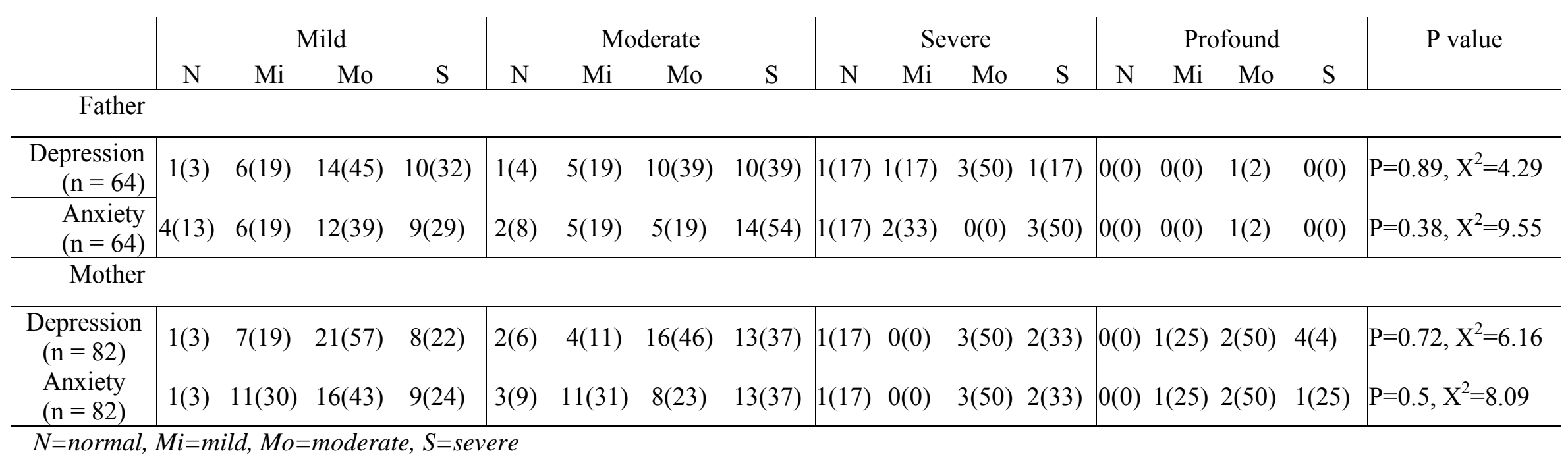


Fathia H Shabo et al. Psychosocial Impacts of Mentally Retarded Children on Parents in Sudan

Table 5: Social participation of the parents in relation to the number and age of the mentally retarded child in the family. Number (\%)

\begin{tabular}{l|c|c|c|c} 
& As usual & Partial & No participation & P value \\
\hline \multicolumn{1}{c|}{ Father $(\mathbf{n}=\mathbf{6 4})$} & & & & \\
No. of MR children & & & & $\mathrm{P}=0.23, \mathrm{X}^{2}=5.50$ \\
One- & $35(62.5)$ & $16(28.6)$ & $5(8.9)$ & \\
- Two + & $4(50)$ & $3(37.5)$ & $1(12.5)$ & \\
\hline Age (yr) & & & & $\mathrm{P}=0.04, \mathrm{X}^{2}=6.13$ \\
$-5-12$ & $8(50)$ & $4(25)$ & $4(25)$ & \\
$->12$ & $31(64.6)$ & $15(31.3)$ & $2(4.2)$ & \\
\hline Mother $(\mathbf{n}=\mathbf{8 2})$ & & & & \\
No. of MR children & & & $9(12.9)$ & \\
One- & $46(65.7)$ & $15(21.4)$ & $2(16.7)$ & \\
- Two + & $7(58.3)$ & $3(25)$ & & $\mathrm{P}=0.83, \mathrm{X}^{2}=1.46$ \\
\hline Age (yr) & & & $4(20)$ & \\
$-5-12$ & $11(55)$ & $5(25)$ & $7(11.3)$ & \\
$->12$ & $42(67.7)$ & $13(21)$ & $\mathrm{X}^{2}=1.34$ \\
\hline
\end{tabular}

Table 6: Degree of severity of MR of the child in relation to marital stability and social participation of the parents. Number (\%)

\begin{tabular}{|c|c|c|c|c|c|}
\hline & Mild & Moderate & Severe & Profound & $\mathrm{P}$ value \\
\hline \multicolumn{6}{|l|}{ Father $(n=64)$} \\
\hline Marital stability & & & & & $\mathrm{P}=0.10, \mathrm{X}^{2}=10.54$ \\
\hline Nothing- & $23(74.2)$ & $13(50)$ & $1(16.7)$ & $1(100)$ & \\
\hline - Divorce & $1(3.2)$ & $4(15.4)$ & $2(33.3)$ & $0(0)$ & \\
\hline - Strong relationship & $7(22.6)$ & $9(34.6)$ & $3(50)$ & $0(0)$ & \\
\hline - Another marriage & $0(0)$ & $0(0)$ & $0(0)$ & $0(0)$ & \\
\hline - Continuous discord & $0(0)$ & $0(0)$ & $0(0)$ & $0(0)$ & \\
\hline Social participation & & & & & $\mathrm{P}=0.5, \mathrm{X}^{2}=8.09$ \\
\hline - As usual & $22(71)$ & $13(50)$ & $3(50)$ & $1(100)$ & \\
\hline -Less than before & $8(25.8)$ & $9(34.6)$ & $2(33.3)$ & $0(0)$ & \\
\hline - No participation & $1(3.2)$ & $4(14.4)$ & $1(16.7)$ & $0(0)$ & \\
\hline \multicolumn{6}{|l|}{ Mother $(\mathrm{n}=82)$} \\
\hline Marital stability & & & & & $\mathrm{P}=0.51, \mathrm{X}^{2}=11.9$ \\
\hline Nothing- & $17(46)$ & $25(71.4)$ & $2(33.3)$ & $2(50)$ & \\
\hline - Divorce & $4(10.8)$ & $4(11.4)$ & $1(16.7)$ & $1(25)$ & \\
\hline - Strong relationship & $15(40.5)$ & $5(14.3)$ & $3(50)$ & $1(25)$ & \\
\hline - Another marriage & $1(2.7)$ & $0(0)$ & $0(0)$ & $0(0)$ & \\
\hline - Continuous discord & $0(0)$ & $1(2.9)$ & $0(0)$ & $0(0)$ & \\
\hline Social participation & & & & & $\mathrm{P}=0.5, \mathrm{X}^{2}=8.09$ \\
\hline - As usual & $28(75.7)$ & $22(62.9)$ & $2(33.3)$ & $1(25)$ & \\
\hline - Less than before & $5(13.5)$ & $8(44.9)$ & $3(50)$ & $2(50)$ & \\
\hline - No participation & $4(10.8)$ & $5(14.2)$ & $1(16.7)$ & $1(25)$ & \\
\hline
\end{tabular}


However, the social participation of the father showed significant association with the younger age (5-12years) of mentally retarded children While mother's participation didn't show such association and no relation with the age or number of children with MR (Table 5).

No significant association was found between the severity of MR and marital stability and social participation (Table 6).

\section{Discussion:}

This is an update study carried out in Sudan to investigate the social and psychological impacts of mentally retarded children on their parents. The study indicated that the number of the males exceeds that of the females' retarded children and is approximately double the females. Our result agrees with many reported figures in literature ${ }^{3,4}$. Similar findings were previously reported in Sudan ${ }^{5}$.

In the current study, none of the children attending the special education centres in Khartoum was below five years of age. The reason behind this was not exactly known, but it might be due to the observation that families prefer to keep their younger mentally retarded children at home and take them to school when they get older, hoping to improve the situation and have some relief while the children are not at home.

Furthermore, the degree of the severity of MR of the children in the present study corresponds with the international categorization. However, mild MR in this study was found in $48 \%$ whereas in many other studies it represent up to $85 \%$. The explanation of this difference may be due to the findings that many children with mild MR join the community and were not diagnosed as mentally retarded and so they attend normal schools. This might be a risk for them because they may not find the necessary attention from the teachers and so they do not progress well.

There is an apparent rise in the percentage of children with moderate degree of MR correspond to previous studies ${ }^{6}$. This may be partly due to increased recognition by families for the need to send those children to special centres for further education and training. There may be a bias that those selected in our study are mostly the difficult children who do not fit the normal stream schools. Most of the families (more than $85 \%$ ) had only one mentally retarded child similar to previous results obtained elsewhere (unpublished data).

Regarding the effects on the parents, some mothers and none of the fathers commented that the presence of the mentally retarded child in the family and his/her care leads to a continuous discord with the spouse (Fig1). Similar to what was found before some mothers felt irritable and liable to quarrel with their spouses. In the present study only one mother said that her husband married a second wife as a result of having a child with MR from his first wife. This is different from the negative impacts on the marital life reported before (unpublished data).

Gelder et.al reported that although parents adjusted psychologically, they were still faced with many prospects of work frustration and social problems ${ }^{7}$. This contrasts the finding in this study. Similar to the present study, Aarhus-Denmark Dupont (1980) showed that families who had a child with MR at home devoted 7 hours a day, 7 days a week to the care of the child, only one quarter of the children could be left alone for as long as half an hour, $77 \%$ had reduced contacts with friends and $59 \%$ had stopped going on holidays $^{8}$.

According to our study, mothers reported that their social life was affected significantly. This goes with other reports ${ }^{8}$.

Most of the parents in this study experienced different degrees of anxiety and depression (Fig. $3 \& 4$ ) and only a small number of parents $(4.7 \%$ of the fathers and $4.9 \%$ of the mothers) had a normal score on HADS for depression. This agreed with Tomkiewicz and Marcia findings ${ }^{9,10}$.

Furthermore, the study showed no significant association between the social and psychological impacts and the number and age of the mentally retarded children or the degree of severity of MR (Tables 1-6). It is difficult to explain that but one reason could be the small sample included in the study. 
The study has certain limitations that should be taken into account. One of these was the fact that the sample size was small. Moreover, the IQ test was carried out prior to the study and not developed by the researcher. Nevertheless, the used IQ test was devised six months prior the beginning of the study.

\section{Conclusion}

There is a heavy burden due to the presence of mentally retarded children on their parents. The total number of mentally retarded males exceeds females and the different degrees of MR amongst children are consistent with previous findings. The presence of Mentally Retarded child in the family is not a cause of negative impact on the marital stability in most of the families.

The negative effects of presence of a mentally retarded child in the family on the social participation of his or her parents did not appear in most of the families. When this occurred the negative effect is mainly on the mothers. There is no significant relationship between the effect on the social participation of fathers and the age of the mentally retarded child, the number of mentally retarded children in the family or the degree of MR. Most of the parents experience different degrees of depression mainly of moderate and severe degrees due to MR of their child as stated in the previous studies. It is important to note that the degree of depression of the parent is neither significantly affected by the number of mentally retarded children, their age nor by the degree of the severity of their mental retardation.

Most of the parents experienced moderate and severe degrees of anxiety. As in depression, the degree of anxiety is not affected significantly by the age of the child, the number of mentally retarded children in the family or the degree of severity of MR.

The study recommends preventative measures to reduce the factors that lead to mental retardation. It also recommends the provision of rehabilitation services and training of children in schools and special institutes, besides supporting their families psychologically and socially to reduce their burden.

\section{References}

1. WHO. Primary Prevention of Mental Neurological and psychological Disorders, Geneva 1998. 8-53

2. Fourth Population Census of Sudan (1993), final tabulations, Sudan Northern States Vol.2, Economic and social characteristics Department of Statistics, Census office Khartoum June 1995; 11:151- 59.

3. Kaplan H.I and Sadock B.J. MR Synopsis of psychiatry behavioural sciences, clinical psychiatry $8^{\text {th }}$ edition Williams and Wilkin. USA. 1997:1137-54

4. Gilberg C. Physical investigation in MR. J Child Psychology and Psychiatry and Allied Disc. 1997; $889-97$.

5. Saeed M.J. Fourth population Census of Sudan (1993) Analytic report; 281-288.

6. Kaplan H. I. and Sadock B. J. Comprehensive textbook of Psychiatry $4^{\text {th }}$ Williams and Wilkin. USA 1989:1728-71.

7. Gelder M., Gath D., Mayou R. and Cowen P. Oxford Textbook of Psychiatry. $3^{\text {rd }}$ edition, Oxford University Press. London 1996. 724-48.

8. Rutter M., Taylor E. and Herosove L. Child And Adolescent Psychiatry. $3^{\text {rd }}$ edition Blackwell Scientific Publication. London 1995:616-40.

9. Tom Kiewicz S. The life of parents with handicapped children, Inserm, unite 69, Montronge, France. Pediatrics 1987; 42 (5):375- 382.

10. Jung $\mathrm{Hu}$, Jin-Ding Lin, Chia-Feng Yen, Ching-Hui Loh, Shang-Wei Hsu, Lan-Ping Lin, Sheng-Ru Wu. Effectiveness of a stress-relief initiative for primary caregivers of adolescents with intellectual disability. Journal of Intellectual and Developmental Disability Mar 2010, Vol. 35, No. 1: 29-35. 